УАK 316.334 .2

ББК 60.561 .7

DOI 10.22394/1682-2358-2021-6-92-101

N.B. Zazaeva, Doctor of Science (Philisophy), Professor of the Social Communications Department, Povolzhsky Institute of Management named after P.A. Stolypin, Branch of the Russian Presidential Academy of National Economy and Public Administration

S.M. Fedyunina, Doctor of Science (Sociology), Head of the Social Communications Department, Povolzbsky Institute of Management named after P.A. Stolypin, Branch of the Russian Presidential Academy of National Economy and Public Administration

\section{MAIN TRENDS \\ IN THE DIGITAL SPACE FORMATION OF RUSSIAN CORPORATE PHILANTHROPY}

The factors that influenced the transfer of companies' charitable activities to the digital space, as well as its structure, are considered. New aspects of traditional corporate philanthropy practices are investigated. It is noted that mass level of communications in the digital space contributes to the implementation of charitable activity model as a tool of social change.

Key words and word-combinations: corporate charity, charity areas, digital charity space, corporate online donation platforms, pro bono platforms.
Н.Б. ЗазаеЊа, доктор философских наук, профессор кафедри сочиальньгх коммуникачий ПоВолжского института утравления имени П.А. Стольпина - филиала Российской академии народного хозяйства и государственной служби при Президенте РФ (email:zazaeva@mail.ru)

С.М. Федюнина, доктор соииолопиеских наук, профессор, заведуюшиии кафедрой сочиальньих коммуникаций Поволжского института управления имени П.А. Стольтпина - филиала Российской академии народного хозяйства и государственной службьл при Президенте РФ (email:smf777@bk.ru)

\section{ОСНОВНЫЕ ТЕНАЕНЦИИ ФОРМИРОВАНИЯ ЦИФРОВОГО ПРОСТРАНСТВА РОССИЙСКОЙ КОРПОРАТИВНОЙ БААГО-

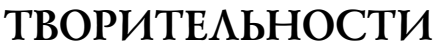

Аннотация. Рассматриваются факторы, повлиявшие на перенос благотворительной деятельности компаний в цифровое пространство. Исследуются новые аспекты традиционных практик корпоративной благотворительности. Отмечается, что массовый уровень коммуникаций в цифровом пространстве способствует реализации модели благотворительной деятельности как инструмента социальных изменений.

Ключевые слова и словосочетания: корпоративная благотворительность, направления благотворительности, цифровое пространство благотворительности, платформы pro bono. 


\section{$\bigsqcup$}

ифровая трансформация современного российского общества повлияла на отечественные практики корпоративной благотворительности. Она существенно расширила цифровое пространство благотворительности, включающее в себя корпоративные платформы ониайн-пожертвований, пкатформы pro bono, сайты коммерческих организаций. В рамках благотворительной деятельности компаний появицись новые виды взаимодействия бизнеса с НКО в онлайн-среде. Они позволици вывести корпоративную благотворительность на уровень массовых коммуникаций, что способствовало реализации модели благотворительной деятельности как инструмента социальных изменений. В этом контексте цифровое пространство стало выступать важнейшим механизмом обеспечения эффективной коммуникации бизнеса с НКО, достаточной информированности мюдей о деятельности НКО и об их сотрудничестве с компаниями.

Три важных фактора повлияли на активный перенос благотворительной деятельности компаний в цифровое пространство. Во-первых, изменение в подходах к благотворительной деятельности российских компаний, связанное с интерпретацией корпоративной бкаготворительности как социальных инвестиций. Согласно данным исследования

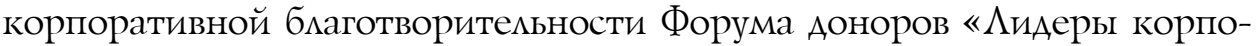
ративной благотворительности - 2020», 78\% компаний-респондентов в качестве приоритетов своей благотворительной деятельности выделили решение социальных проблем, 54\% - развитие регионов присутствия, $43 \%$ - актуальность и социальную значимость проблемы [1, с. 24].

Ориентация компаний на реацизацию благотворительных проектов, создающих ценность как Аля компаний, так и Амя общества, задало новые требования к корпоративной благотворительной деятельности в виде ее системности, результативности и расширении коммуникативности. Последнее подразумевает активные практики вовлечения в совместную благотворительность всех заинтересованных сторон от $\mathrm{HKO} \mathrm{Ао} \mathrm{массовой} \mathrm{аудитории.} \mathrm{Не} \mathrm{случайно} 25 \%$ российских компаний отметили, что важным мотивом выбора конкретного благотворительного проекта является развитие партнерств. При этом $76 \%$ компаний относят НКО к наиболее приоритетным группам партнеров в этой сфере [1, с. 8]. Традиционными формами партнерства бизнеса и НКО явцяются грантовые программы по поддержке НКО, более современные формы - совместные фандрайзинговые кампании, активно используемые крупными коммерческими организациями, такими как Сбербанк, JTI, Синара, Росбанк, Amway. Именно они широко представлены на различных платформах онлайн-пожертвований. 
Зарубежкный опыт также демонстрирует новые практики взаимодействия НКО и бизнеса на основе цифровых технологий. Например, крупнейшая платформа-агрегатор $\mathrm{HKO}$ в Великобритании Charity Choice объединяет более 160000 благотворительных фондов [2]. В цифровом пространстве создаются базы данных всех субъектов бцаготворительности, что значительно облегчает поиск Аруг Аруга и взаимоАействие межАу ними.

В Рунете присутствие НКО и компаний на платформах-агрегаторах гораздо меньших масштабов. ОАной из самых крупных платформ-агрегаторов стала Мывместе.рф, на ней осуществляют благотворительную деятельность около 9000 организаций. Успешность этого электронного проекта связана с поддержкой государства. Все остальные платформы онлайн-пожертвований аккумулируют менее Авухсот НКО. Наибольшее число HКО собрано на «Аобро.Mail.Ru» - 188 фондов, на большинстве остальных платформ около ста НКО. Более скромный российский масштаб сотрудничества в цифровом пространстве свидетельствует о том, что потенџиал электронного формата партнерства еще далеко не использован. Итак, практики корпоративной бцаготворительности как интеграции социацьной ответственности и миссии компании требуют совместного коммуникативного пространства, объединяющего НКО, компании и массовую аудиторию.

Во-вторых, важным фактором, придавшим существенный импульс развитию коммуникаций в цифровом пространстве, стало все более возрастающее положительное отношение российской массовой аудитории к благотворительности и осознание необходимости участия бизнеса в ней. Согласно исследованию российского благотворительного фонда САF (2020 г.), 63\% респондентов (по сравнению с 55\% в 2019 г.) подчеркнули, что благотворительные организации положительно повлияли на жизнь в России в целом [3]. Как следствие, социально ответственная организация, сотрудничающая с НКО, приобретает существенное преимущество в глазах массовой аудитории. Так, $58 \%$ россиян отметили, что более склонны покупать продукт или услугу у компании, которая жертвует на благотворительные цели или поддерживает местные сообщества. Среди мюдей в возрасте 25-34 мет, являющихся наиболее активными пользователями разнообразных электронных ресурсов, их количество Аостигло 66\% [3]. Благодаря такому положительному сАвигу в общественном сознании практики сощиально ориентированного маркетинга с использованием технологий соџиального брендинга или «бренда со смыслом» стали более актуальными дмя российского бизнеса и выступили существенным мотивом для его благотворительной деятельности. Это подтвердили данные исследования корпоративной 
благотворительности Форума доноров «Аидеры корпоративной благотворительности - 2020». В качестве одной из основных целей корпоративной благотворительности $38 \%$ российских компаний в 2020 г. отметили укрепление репутации на рынке товаров и услуг [1, с. 5]. Следовательно, сдвиги в общественном мнении и обшественном сознании потребовали от компаний большее внимание уделять работе с массовой аудиторией, побудили их к поиску новых методов PR-сопровождения своей благотворительной деятельности в рамках соџиально ориентированного маркетинга.

В-третьих, бурное развитие цифровых технологий повлекло разнообразие онлайн-форматов фандрайзинга, что обеспечимо участие в благотворительной деятельности массовой аудитории. По Аанным исслеАования фонда CAF, в 2019 г. впервые Аоля россиян, осуществляющих пожкертвования ониайн (43\%), привысила долю тех, кто делал пожертвования наличными (39\%). Из них $16 \%$ респондентов осуществляли пожертвования через эмектронные кошельки и $37 \%$ - через СМС. Наконец, 34\% респондентов 18-24 иет указали, что их стимулирует совершать пожертвования цучший доступ к платежным инструментам [3], обеспечиваемый через платформы онлайн-пожкертвований. Их первой и главной функцией оказалось предоставление возможности массовой аудитории просто и быстро совершать пожертвования.

Развитие платежкных сервисов создало техническую основу дия сбора массовых пожертвований, что позволило привлечь к благотворительной деятельности не только массовую аудиторию, но и компании. Формат онлайн-коммуникаций оказался оптимальным и плодотворным, поскольку совместил сбор средств на благотворительные проекты и информирование массовой аудитории о социально важной деятельности, которую ведут как НКО, так и компании. 92\% корпораций-благотворителей сообщили, что используют Аля PR-сопровождения благотворительной деятельности разнообразные интернет-ресурсы от корпоративных сайтов до социальных сетей; $30 \%$ компаний отметили, что используют Аля продвижения совместных фандрайзинговых кампаний, платформы-агрегаторы онлайн-пожертвований [1, с. 37]. Это означает, что PR-деятельность корпоративной благотворительности стала точнее направляться на целевые аудитории, что позволило ей более убедительно отражжать корпоративную социальную деятельность компаний. Таким образом, развитие платежных сервисов, обскуживающих разнообразные электронные ресурсы благотворительности, стимулируют массовую аудиторию к более активному участию в благотворительности и тем самым предоставцяют компаниям новые возможности работы с общественным мнением. 
В корпоративной бцаготворительности значительное место начали занимать мэтчинговые программы на платформах онлайн-пожертвований. Компании стали расходовать благотворительные бюджеты на работу с НКО через платформы онлайн-пожертвований, участвуя в «мэтчинговых» акциях, финансируя наиболее успешные, а значит, и попумярные у массовой аудитории благотворительные проекты. Зарубежный опыт свидетельствует, что в практиках мэтчинга не только компания побуждается к участию в том $\Lambda и$ ином проекте за счет его обшественного резонанса, но и массовая аудитория становится более активной. По данным Double the Donation, в США 84\% частных благотворителей отмечали, что с большей вероятностью пожертвовали бы Аеньги, если бы они были удвоены [2]. Хотелось бы верить, что Аля российской массовой аудитории это тоже может иметь побуждающий эффект.

Компании не ограничиваются только мэтчинговыми программами на платформах онлайн-пожкертвований. В российской благотворительности появицось новое направление - создание корпоративных эмектронных ресурсов благотворительности. Его главная особенность в том, что компании стали вкцадывать средства не в программы, предлагаемые на уже существующих платформах онлайн-пожертвований, а создавать собственные аналогичные ресурсы, активно взаимодействуя в НКО. ГАавными объектами нового направления бцаготворительности стали корпоративные платформы онцайн-пожертвований, платформы pro bono.

Наряду с диверсифицированными благотворительными фондами при крупных компаниях появляются корпоративные платформы онмайн-пожертвований. Единичные корпоративные платформы, созданные в 2013 г., продемонстрировали успешность этого начинания, и сегодня эти практики благотворительности можно смело назвать распространенными [4, с. 177] .

Первыми в новом направлении корпоративной благотворительности были компании, работающие в сфере IT-технологий. Mail.Ru Group организовала одну из первых платформ онлайн-пожкертвований «Аобро Mail.ru», платежкный сервис QIWI платформы «Всем» и \#надобро, Яндекс - «Помощь рядом». Затем это направление благотворительности стали активно использовать российские банки, демонстрируя разнообразие онлайн-форматов фандрайзинга. В настоящее время успешно работают платформы онлайн-пожертвований «САелай» от СМП-Банка, «Сбербанк Вместе» от Сбербанка, «Кэшбэк во благо» банка «Тинькофф».

Корпоративные платформы онцайн-пожертвований позволяют че- 
рез фандрайзинг привлекать внимание массовой аудитории к благотворительной деятельности компании. Взаимодействие бизнеса, НКО и массовой аудитории осуществмяется в рамках сбора средств Амя благотворительных проектов. Важно, что компания не просто передает деньги благотворительным организациям на проекты, которые быстро собирают массовые пожертвования, а выступает организатором и финансистом самого коммуникативного пространства НКО и массовой аудитории, что полностью снимает пробцему поиска и отбора бцаготворительной организации для сотрудничества. Наконец, в области PR-сопровождения благотворительной деятельности эта практика свидетельствует об акценте на репутационной ориентаџии данных корпоративных благотворительных программ.

Новое направление благотворительности не ограничивается корпоративными платформами онлайн-пожкертвований. К ним присоединяются платформы-агрегаторы, созданные совместно НКО и коммерческой организацией не только дмя фандрайзинговых кампаний. Безусловно, сбор средств на благотворительные проекты для НКО явмяется неотъемлемым условием их деятельности, но «помощь делом» через предоставление квалифицированной консультативной помощи оказывается Аля благотворительной организации не менее значимым, поэтому направление корпоративной благотворительности стало расширяться за счет платформ, работающих на условиях pro bono. K ним относится платформа ProCharity, созданная фондом «Арузья» совместно с Mastercard. Аанный эмектронный ресурс не привлекает пожертвования, а задействует помощь делом. ЗАесь такие известные коммерческие компании, как KAPO, «Нетология», McKinsey, помогают благотворительным организациям по десяти направлениям, от IT до менеАжмента и финансов. Аанные практики интересны как пример совершенствования коммуникации бизнеса и НКО в рамках помощи делом. Ускуги pro bono в своей благотворительной деятельности и активно успешно применяют 59\% компаний, как правило, в оффмайн-режиме [1, с. 16]. Применение цифровых форматов «помощи делом» придает этому виАу бцаготворительности не просто новый формат, а новое качество. Пцатформы pro bono позволяют быстрее и проще получить необходимую квалифицированную профессиональную помощь в управлении и организаџии НКО, что способствует их профессионализации.

Корпоративные платформы онлайн-пожертований и платформы pro bono призваны решать проблемы коммуникаций с НКО и тем самым сушественно повышают уровень корпоративной соџиальной деятельности, в то же время работают с массовой аудиторией, создавая серьезный репутационный актив компаний. Наряду с новым направ- 
мением благотворительности компании по-прежнему активно используют корпоративный сайт как традиционный инструмент массовых коммуникаций. Согласно исследованию PR-сопровождения корпоративной благотворительности 98\% компаний, занимающихся бцаготворительной деятельностью, стали размещать на своих сайтах отчеты о ней [5, с. 11]. Аинейное информирование массовой аудитории через эмектронные ресурсы о своей соџиально важной деятельности явмяется необходимым Аля формирования имиджа социально ответственной компании, но этого недостаточно. Сегодня корпоративный сайт выступает как инструмент оповещения массовой аудитории о деятельности $\mathrm{HKO}$, а вместе с тем и компании. Так, сайт компании Maps.me, преАоставляющей карты различных стран мира дия путешественников, размещает на них все пункты по сбору ненужной одежкы благотворительного фонда «Второе Аыхание». Сеть магазинов «Вкусвимм» публикует в своем прицожкении объявления о пропаже цюдей от поисково-спасательного отряда «Аиза Алерт». Таким образом, корпоративный сайт позволяет сделать коммуникаџии компании с массовой аудиторией, в первую очередь со своими потребитемями, более интерактивными и эффективными, существенно дополнив прямое информирование о благотворительной деятельности компании сообщениями, необходимыми Аля деятельности НКО.

Коммуникативные практики digital-подарков соединяют воедино компании, НКО, массовую аудиторию частных благотворителей. Аигитальные подарки - это бесплатные подписки на образовательные интернет-ресурсы, музыку, электронные бибциотеки, фимьмы. Они Аарятся активным жертвователям платформ онлайн-пожертований, а также сотрудникам компаний, которые отказались от сувенирного бюджета в пользу благотворительного фонда. Так благотворительные организации поощряют частных благотворителей, а компании помогают НКО, жертвуя свои услуги и сувенирные бюджеты. С оАной стороны, digital-подарки выполняют известную функцию поощрения частных благотворителей, что АОлжно стать Аополнительным стимулом Аля их дальнейшего участия в благотворительности. С Аругой стороны, электронный формат рассчитан на конкретную цемевую аудиторию продвинутых пользователей, посетителей Сети, то есть уровень массовых коммуникаций. Итак, мэтчинговые акции, информация о НКО на корпоративных сайтах и дигитальные подарки обеспечивают массовые коммуникации компаний с потребитемями в рамках соџиально ориентированного маркетинга.

Наконец, еще более важным элементом цифрового пространства благотворительности, сушественно вцияюшего на повышение систем- 
ности и Аолгосрочности корпоративной благотворительности, становятся платформы-агрегаторы на основе социального партнерства. Ярким примером может служить информаџионный ресурс Мывместе. рф. Аанная платформа поА эгидой государства призвана собрать соџиальные инициативы и объединить для их воплощения всех соџиальных субъектов. При этом приоритеты соџиальных изменений на платформе вписаны в цели национального развития. Ориентация компаний на решение социальных проблем в рамках целей национального развития побуждает их вписывать корпоративную благотворительность в общую бизнес-стратегию. Она призвана обеспечить устойчивое развитие бизнеса в Российском государстве с учетом существующих экономических, социальных и экологических проблем. Вовлечение компаний в Аостижение целей национального развития объективно превращает корпоративную благотворительность в один из элементов корпоративных социальных инвестиций. Это способствует качественному росту корпоративной благотворительности, связанному с увеличением ее направлений. Наряду с уже известными направлениями социальной деятельности компаний (поддержка образования, здравоохранения, экологии, соџиальной защиты) появцяются новые направления в виде благоустройства городской среды, использования цифровых технологий в жизни сообществ. Пиатформа Мывместе.рф включает три группы проектов: премия \#Мывместе; проект по реализации инициатив в обмасти социального комфорта - \#одобрено; проект оказания психологической подАержки по специальной горячей цинии - психологическая помощь. КажАая из групп демонстрирует новые виды взаимодействий НКО, волонтеров и компаний. В разделе «Психологическая помощь» бизнес активно участвует в разработке и технической поддержке чатбота по оказанию бесплатной психологической поддержки. Это такие компании, как Rakuten, Viber, VK, Telegram.

Премия \#Мывместе включает в себя четыре направления: «Волонтеры и НКО», «Бизнес, «Медиа» и «Международное сотрудничество». Последние три призваны поощрить и отметить благотворительную деятельность компаний. Выдемяя кучшие проекты в корпоративной благотворительности, способствующие достижению национальных целей, государство предоставляет бизнесу уникальную информацию о приоритетных социальных пробцемах. К ним относятся вопросы защиты окружающей природы, поиска пропавших, развитие культурных ценностей и традиций, а также внедрение цифровых технологий. Например, среди восьми номинаций в разделе «Бизнес» премии \#Мывместе есть номинация «Технологии Аля жизни», посвященная проектам, направленным на создание или распространение цифровых продуктов 
Аля улучшения качества жизни житемей страны в рамках наџиональной цели «Цифровая трансформация». Таким образом, новое направмение корпоративной благотворительности оказывается актуацьным и значимым не только с точки зрения общества, но и государства.

Премия позволяет не просто объединить активных благотворителей, но и создать новые возможноости для корпоративной благотворительности как инструмента социальных изменений. Электронный формат премии выступает как база данных субъектов благотворительности. На платформу уже поступило свыше 25 тысяч заявок, из них на направление «Бизнес» подали заявки 5,5 тысячи разнообразных коммерческих организаций от крупных компаний и холдингов до преАставителей мокального, местного бизнеса [6].

Важной составмяющей премии явмяются виды поощрения победителей. Аля компаний в рамках модели корпоративной благотворительности как соџиальных инвестиций они оказываются значимыми - это «Национальное признание», статус «Партнер национальных проектов» (присуждается АНО «Начиональнье приоритеть» по решению Правительства PФ), специальные благодарности чиенам команды от руководства страны. Такие поошрения позволяют улучшить отношение с государством, существенно повысить уровень репутаџии и доверие к компании, узнаваемость бренда как социально ответственного.

Значимым видом поощрения Амя компаний-благотворителей явАяется PR-сопровождение мучшего корпоративного проекта, придающее ему широкую известность. Это, к примеру, медиасопровождение от AНО «Национальные приоритеты» и партнеров премии; продвижение социальной рекламы на ведущих площадках Рунета и участие в акселераторе от АНО «Институт развития интернета»; публикация в специальном сборнике Амя тиражирования; сопровождение со стороны организаторов премии. Кроме того, победителям предоставляются обучающие программы: прохождение образовательной программы в мастерской управления «Сенеж» в 2022 г. и участие в образовательной стажировке Программы мобимьности [7]. Таким образом, премия «\#Мывместе» выступает важным стимулом Амя развития соџиальной Аеятельности компаний и профессионализации российской корпоративной благотворительности.

Итак, цифровые технологии существенно повлияли на корпоративную благотворительность, создав пубцичное пространство массовых коммуникаций как дмя проведения фандрайзинговых кампаний, так и Амя более широкой совместной деятельности бизнеса, НКО, массовой аудитории по решению социально важных проблем. Это способствовамо изменению стратегий корпоративной благотворительности, которая 
стала рассматриваться компаниями как соџиацьные инвестиции, способствующие устойчивому развитию бизнеса. Наиболее важным следствием этой тенденции можно считать появцение нового направцения благотворительности - создание корпоративных электронных ресурсов благотворительности. Оно включает в себя корпоративные платформы онлайн-пожертвований, платформы pro bono и нашло одобрение со стороны государства. Но только им корпоративная бцаготворительность в цифровом пространстве не ограничивается. Мэтчинговые программы на платформах онмайн-пожертвований, информация о НКО на корпоративных сайтах и Аигитальные подарки Аля частных благотворителей явцяются традиционными практиками корпоративной благотворитецьности. Аацьнейшее расширение цифрового пространства благотворительности связано с появлением платформы-агрегатора, призванной собрать всех участников благотворительной Аеятельности поА эгиАой государства. Она позволяет бизнесу принять участие в соџиальных проектах, соответствующих цемям национального развития и становится важным стимулом Аля Аацьнейшего развития корпоративной благотворительности. Разнообразие практик электронной благотворительности позволяет надеяться, что компании в Аальнейшем будут активно участвовать в соџиальной повестке, инвестировать в решение соџиально важных и насущных проблем современного российского общества.

\section{Библиографический список}

1. Все о лидерах 2020: по материалам проекта «Лидеры корпоративной благотворительности - 2020». М., 2020.

2. Шергова E. Как Coca-Cola, Netflix и другие гиганты занимаются благотворительностью: главные тренды КСО в мире и России. URL: https://www.forbes.ru/forbeslife/413169

3. Исследование частных пожертвований в России - 2020: Обзор тенденций частной благотворительности в России. М., 2020.

4. Зазаева Н.Б., Федюнина С.М., Морохова Е.И. [и др.]. Управление коммуникациями в эпоху цифровизации: монография / под ред. Н.Б. Зазаевой. Саратов, 2020.

5. Максимова Д.И. Информационно-коммуникативный аспект благотворительной деятельности корпораций. Коммуникология: электронный научный журнал. 2020. Т. 5, № 3. С. 8-18.

6. На участие в Международной премии \#МЫВМЕСТЕ поступило 25 тысяч заявок. URL: https://премия.мывместе.pф//tpost/4dfzubcj61-na-uchastie-v-mezhdunarodnoi-premii-mivm

7. Что получает победитель. URL: https:/премия.мывместе.pф 